It is not feasible to attempt to compress all the experimental data or the tentative theoretical conclusions into a short letter of this nature.

Peter M. Milliman

(Dominion Observatory)

D. W. R. MoKINLEY

(National Research Council of Canada)

Ottawa.

Miriam S. Burland

Dec. 8.

(Dominion Observatory)

Bateman, $R$ Mcrish A. (1946). Pierce, J. A., Phys. Rev., 71, 88 (1947). Appleton, Sir Edward, and Naismith, R., Proc. Phys. Soc., 59, 461 (1947). Hey, J. S., and Stewart, G. S., Proc. Phys. Soc., 59, 858 (1947). Papers by Prentice, J. P. M., Lovell, A. C. B., and Banwell, C. J., and by Lovell, A. C. B., Banwell, C.

THE results obtained by Dr. Millman and his colleagues represent an important contribution to the study of the complex radio echo phenomena which are observed on wave-lengths longer than $8 \mathrm{~m}$. Recent unpublished British work has a significant bearing on some of the issues raised and a short summary may be appropriate.

Effect of Radio Wave-length. Simultaneous observations on two or more wave-lengths have been made of the transient echoes originating in the $100 \mathrm{~km}$. region of the atmosphere, from which it appears that a striking change occurs as the wave-length is decreased from $8 \mathrm{~m}$. to $6 \mathrm{~m} .^{1}$. Above $8 \mathrm{~m}$. a very large number of radio echoes are observed independently of the presence of a major meteor shower of the 'visible' type. These echoes show a marked diurnal and seasonal variation ${ }^{2,3}$, and are believed to be due to a uniform distribution of minute dust through which the earth is passing. As the radio wavelength is decreased, this high echo-rate disappears, and, on $6 \mathrm{~m}$. and less, the transient echoes arise only from the meteors associated with the visible streams emanating from definite radiants.

Aspect Sensitivity and the Scattering Process. On wave-lengths less than $6 \mathrm{~m}$. the main radio echo is obtained only when the meteor crosses the perpendicular from the station to the trail. This is immediately evident when observations are made with a highly beamed aerial system. Thus, near the peak of the great 1946 Giacobinid shower, a directional aerial system was turned into the radiant instead of at right-angles to it, and the echo-rate fell from 50 per minute to less than 0.1 per minute, although at that time the sky appeared to be full of meteors ${ }^{4}$. This aspect sensitivity, and the change in scattered power with wave-length from the same meteor trail, can be explained if the electrons are created by the meteor in the form of a long column of diameter small compared with the wave-length ${ }^{5}$. It has been realized, however, that this picture does not succeed in giving a satisfactory account of the much more complicated phenomena in the wave-length range greater than $8 \mathrm{~m}$., and as Dr. Millman and his colleagues suggest, additional scattering processes must be invoked to explain the high echo-rate from invisible meteors, and the lack of aspect sensitivity.

It seems clear that in the present state of our knowledge the astronomy of the meteor streams can only be studied satisfactorily on wave-lengths less than $6 \mathrm{~m}$., where the aspect sensitivity of the trails can be used to delineate radiant points by such methods as devised by Hey and Stewart ${ }^{6}$, and Clegg? and where the observed echo-rates bear a very close relation to the visible meteor-rate.
The complex phenomena on longer wave-lengths are not yet understood, and further information of the Canadian experiments will be awaited with much interest.

Physical Laboratories,

A. C. B. Lovell

University, Manchester 13.

$$
\text { Feb. } 6 .
$$

${ }^{1}$ Lovell, Phys. Soc. Rep. Progr. Phys., 11 (1948) (in the press).

2 Eckersley, J. Inst. Elect. Eng., 86, 548 (1940).

${ }^{3}$ Appleton and Naismith, Proc. Phys. Soc., 59, 461 (1947).

'Lovell, Banwell and Clegg, Mon. Not. Roy. Ast. Soc., 107 (1947) (in the press).

'Lovell, Nature, 160, 670 (1947).

- Hey and Stewart, Proc. Phys. Soc., 59, 858 (1947).

" Clegg (in the press).

\section{A Submerged Ancient Cliff near Plymouth}

ECHO soundings, made on the Marine Biological Association's research vessel Sabella, have revealed a submarine cliff, suggesting an ancient shore line, about two miles south-south-west magnetic from Plymouth Breakwater Lighthouse (see record reproduced). The height of the cliff at the section is about $33 \mathrm{ft}$., its foot rests at about 22 fathoms below the level of low water springs, while the gradient is of the order 1 in 3.

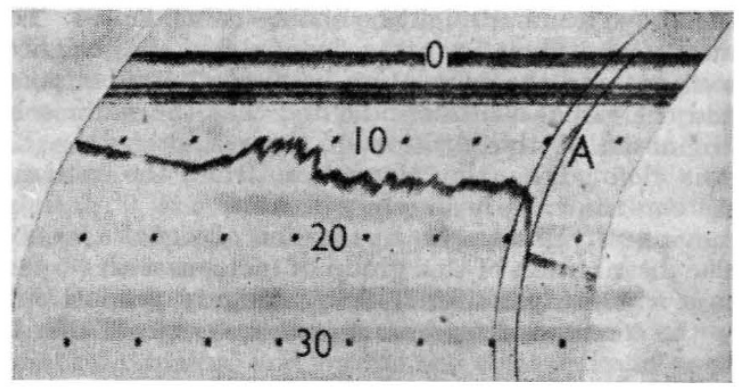

PORTION OF ECHO-SOUNDING RECORD ON COURSE S.S.W. MAGNETIC FROM PLYMOUTH BREAKWATER LIGHTHOUSE

A vertical line below the ship is represented by an are of a circle. The distance between two dots along an arc represents ten fathoms, while the distance between two dots along a horizontal lin represents the passing of $3 \mathrm{~min}$. or about $650 \mathrm{ft}$. run by the ship at a quarter speed

The record of the bottom landward of the submerged cliff in 15 fathoms or less is irregular, suggesting a surface of sub-aerial denudation which has not yet been completely covered with recent deposits. Seaward of the cliff the record, with others, shows a gently sloping smooth platform suggesting a wavecut beach possibly covered with some recent sediments. Sections across the submerged part of the Eddystone show a very rugged topography; nonetheless, there are indications at several points of the foot of a wave-cut cliff at 24 fathoms.

The formation of such a cliff would seem to need a fairly prolonged stand of the sea at a level about 22 fathoms $(40 \mathrm{~m}$.) lower than that of to-day, or perhaps a few fathoms lower still. If similar cliffs exist elsewhere in the English Channel, their further study may help to solve problems of sea-level during the regressions of the sea in the Pleistocene Ice Ages.

Directly above the cliff at the point marked $A$ the record of a shoal of fish may be seen. The fish are reminiscent of birds soaring above a cliff in an ascending current of air. The time was within five minutes of low water at Devonport.

Marine Biological Laboratory,

L. H. N. Cooper

Plymouth. Jan. 8. 